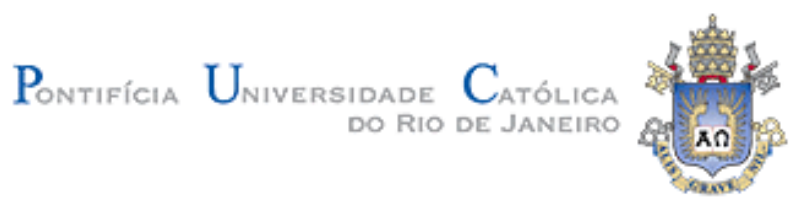

Roberta Fernandes Pacheco

\title{
O Ato de Discordância em Contexto Argumentativo do Espanhol
}

\begin{abstract}
Dissertação de Mestrado apresentada ao Programa de Pós-graduação em Letras, na área de Estudos da Linguagem como requisito parcial para obtenção do grau de Mestre em Letras.
\end{abstract}

Orientadora: Prof ${ }^{a}$ Dra. Maria do Carmo Leite de Oliveira 


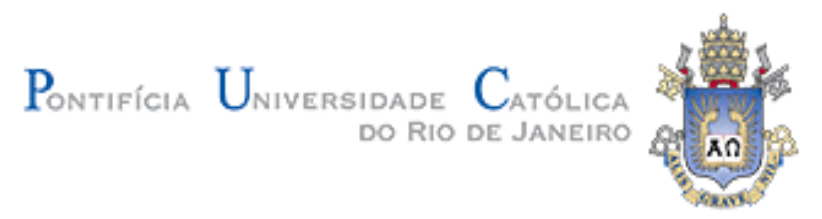

Roberta Fernandes Pacheco

\title{
O ATO DE DISCONDÂNCIA EM CONTEXTO ARGUMENTATIVO DO ESPANHOL
}

\begin{abstract}
Dissertação apresentada como requisito parcial para obtenção do grau de Mestre pelo programa de PósGraduação em Letras do Departamento de Letras do Centro de Teologia e Ciências Humanas da PUC-Rio. Aprovada pela Comissão Examinadora abaixo assinada.
\end{abstract}

Profa. Maria do Carmo Leite de Oliveira Orientadora Departamento de Letras - PUC-Rio

Profa. Maria das Graças Dias Pereira Departamento de Letras - PUC-Rio

Profa. Sonia Bittencourt Silveira UFJF

\footnotetext{
Prof. Paulo Fernando Carneiro de Andrade Coordenador Setorial do Centro de Teologia e Ciências Humanas - PUC-Rio
} de de 
Todos os direitos reservados. É proibida a reprodução total ou parcial do trabalho sem autorização da universidade, da autora e do orientador.

\section{Roberta Fernandes Pacheco}

Graduou-se em Letras Português / Espanhol pela Universidade Federal do Rio de Janeiro em 1999. Em 2002 concluiu o curso de Especialização lato sensu em Língua Espanhola Instrumental para Leitura na Universidade Estadual do Rio de Janeiro. Em 2008 concluiu o curso de Mestrado pela Pontifícia Universidade Católica do Rio de Janeiro. Participou em congressos nacionais e internacionais com apresentação de trabalhos. Sua experiência é centrada na área de Linguística, com ênfase em Lingüística Aplicada, desenvolvendo estudo na área do Espanhol. Atualmente ensina Espanhol como Língua Estrangeira em instituições de nível superior.

Ficha Catalográfica

Pacheco, Roberta Fernandes

$O$ ato de discordância em contexto argumentativo do espanhol / Roberta Fernandes Pacheco; orientadora: Maria do Carmo Leite de Oliveira. -2008.

$136 \mathrm{f.} ; 30 \mathrm{~cm}$

Dissertação (Mestrado em Letras)-Pontifícia Universidade Católica do Rio de Janeiro, Rio de Janeiro, 2008.

Inclui bibliografia

1. Letras - Teses. 2. Discordância. 3. Argumentação. 4. Interação institucional. I. Oliveira, Maria do Carmo Leite de. II. Pontifícia Universidade Católica do Rio de Janeiro. Departamento de Letras. III. Título.

CDD: 400 
A meus pais amados, Domingos e Maria, por confiarem em mim, hoje e sempre.

Obrigada mãe pela inigualável força e sabedoria. 


\section{AGRADECIMENTOS}

Ao final desta jornada acadêmica, devo o meu agradecimento aos meus amigos e familiares pelo carinho e estímulo ao longo dos últimos dois anos, contribuindo para tornar possível o término deste trabalho. Entre eles, no entanto, se faz necessário destacar algumas pessoas que merecem agradecimentos especiais:

Aos meus pais Domingos e Maria, por tudo o que representam em minha vida, pelo incentivo entusiasmado e carinhoso e pelo amor de sempre;

Ao meu irmão Claudio, pela ajuda nos momentos de enfermidade, sendo a minha mão na digitação de partes deste estudo, quando os prazos se esgotavam;

À minha querida orientadora, Maria do Carmo Leite de Oliveira, não só pela orientação atenta durante o desenvolvimento desta dissertação, mas principalmente pela confiança em meu trabalho, pelo imenso carinho que me dedicou nestes anos, além das palavras de incentivo e força;

Às professoras Maria das Graças Dias Pereira e Sonia Bittencourt Silveira, por aceitarem fazer parta da banca examinadora, pelo exemplo profissional, pelo apoio e compreensão;

A minha amiga Dani, pela ajuda e esclarecimento em minhas dúvidas com a língua inglesa, além é claro de seu imenso carinho;

A minha amiga Nanda, pelo empréstimo do computador em momentos fundamentais desta jornada e acima de tudo, pelas trocas de idéias tão proveitosas e pelo incentivo constante;

A meu amigo Leandro, por ser um ouvido a mais na tarefa de transcrever os dados do corpus; 
Às colegas de jornada, Samira e Sabrina, pelo apoio acadêmico e pela parceria em diversos momentos;

E por último, não poderia deixar de agradecer a Deus, que sempre esteve ao meu lado, me confortando e me dando forças para a superação de todos os obstáculos da minha vida. 


\section{RESUMO}

Pacheco, Roberta Fernandes; Oliveira, Maria do Carmo Leite de. O ato de discordância em contexto argumentativo do espanhol. Rio de Janeiro, 2008. 136 p. Dissertação de Mestrado - Departamento de Letras, Pontifícia Universidade Católica do Rio de Janeiro.

O presente estudo tem por objeto de análise seqüências de discordância produzidas num contexto de debate televisivo no idioma espanhol, e seu objetivo é verificar como se realiza o ato de discordância em uma situação argumentativa, observando como os aspectos do contexto situacional e cultural são relevantes para os participantes da interação. Seguindo a perspectiva de um modelo interacional, em que a comunicação é vista como uma atividade conjunta, construída pelos participantes em interação, a abordagem teórica se desenvolve no âmbito da Sociolingüística Interacional e nos pressupostos da Análise da Conversa. A metodologia de investigação compreende a análise qualitativa e interpretativa dos dados de fala gravados do programa de debate político da televisão espanhola denominado 59" (cinqüenta e nove segundos). Para a seleção do corpus, levou-se em consideração o recorte da edição em que a presença de discordância se fez mais recorrente. Observou-se que a estrutura argumentativa é composta pelos elementos posição e argumento, enquanto a estrutura da discordância se apresenta como uma contraposição e um contra-argumento. Observou-se também, que as evidências são base de discordância entre os turnos, uma vez que cada participante as utiliza como instrumentos a seu favor na defesa de suas posições. Na realização da discordância, observou-se que os participantes assim como utilizam estratégias para mitigar o ato, também as utilizam para instigar e fazer avançar a discordância. Concluiu-se, portanto, que a discordância é constituinte do contexto argumentativo, envolvendo os participantes numa disputa pelo o conhecedor da informação e, por conseguinte, o que possui a melhor capacidade de convencimento.

\section{Palavras- chave}

Discordância; Argumentação; Interação Institucional. 


\section{RESUMEN}

Pacheco, Roberta Fernandes; Oliveira, Maria do Carmo Leite de. O ato de discordância em contexto argumentativo do espanhol. Rio de Janeiro, 2008. 136 p. Dissertação de Mestrado - Departamento de Letras, Pontifícia Universidade Católica do Rio de Janeiro.

El presente estudio tiene por objeto de análisis secuencias de discordancia producidas en un contexto de debate televisivo en el idioma español, y su objetivo es verificar como se realiza el acto de discordancia en una situación argumentativa, observando cómo los aspectos del contexto situacional y cultural son importantes para los participantes de la interacción. En base a una perspectiva de un modelo interaccional, en el que la comunicación se presenta como una actividad conjunta, construida por los participantes en interacción, el abordaje teórico se desarrolla en el ámbito de la Sociolingüística Interaccional y en los presupuestos del Análisis de la Conversa. La metodología de investigación comprende el análisis cualitativo e interpretativo de los datos de habla grabados del programa de debate político de la televisión española denominado 59" (cincuenta y nueve segundos). Para la selección del corpus se tomó como base el recorte de la edición en el que la presencia de discordancia se hizo más recurrente. Se observó que la estructura argumentativa es compuesta por los elementos posición y argumento, mientras la estructura de la discordancia se presenta como una contraposición y un contra-argumento. Se observó también, que las evidencias son base de discordancia entre los turnos, una vez que cada participante las utiliza como instrumentos a su favor en la defensa de sus posiciones. En la realización de la discordancia, se observó que los participantes así como utilizan estrategias para mitigar el acto, también las utilizan para instigar y hacer avanzar la discordancia. Se concluye, por lo tanto, que la discordancia es constituyente del contexto argumentativo, que envuelve los participantes en una disputa por el conocedor de la información y por la mejor capacidad de convencimiento.

\section{Palabras Clave}

Discordancia; Argumentación; Interacción Institucional. 


\section{SUMÁRIO}

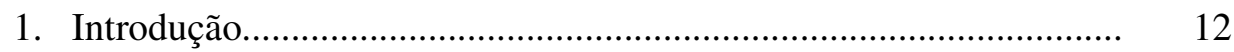

2. Fundamentação Teórica................................................................. 17

2.1. Modelo de Comunicação Interacional................................... 17

2.1.1. Sociolingüística Interacional................................ 19

2.1.2. Análise da Conversa......................................... 22

2.2. A Discordância................................................................... 33

2.2.1. A Discordância e a Preferência........................... 34

2.2.2. Recursos na Realização da Discordância........... 39

2.3. A Argumentação................................................................... 41

3. Aspectos Metodológicos............................................................... 49

3.1. O Programa................................................................. 49

3.1.1. O Cenário......................................................... 51

3.1.2. Os Participantes do Debate................................ 53

3.2. Os Temas do Debate....................................................... 56

3.2.1. Primeiro Tema: O Julgamento........................... 57

3.2.2. Segundo Tema: Denúncias............................... 60

3.2.3. Terceiro Tema: As Eleições Espanholas............. 60

3.3. Os Recortes de Análise..................................................... 62

3.3.1. A Transcrição.................................................. 64

4. A Discordância e a Argumentação..................................................... 66 
4.2. A Estrutura Marcada da Discordância................................ $\quad 82$

4.3. A Realização da Discordância............................................ $\quad 90$

4.3.1. Os Mitigadores................................................... 91

4.3.2. Os Instigadores................................................ 94

5. Considerações Finais................................................................ 104

6. Referências Bibliográficas.............................................................. 110

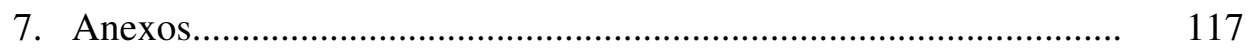

7.1. Convençõoes de Transcrição............................................... 117

7.2. Transcrição do Tema 1 ...................................................... 118

7.3.Transcrição do Tema 2 ..................................................... 126

7.4.Transcrição do Tema 3...................................................... 129 


\section{LISTA DE FIGURAS}

1. Disputa do Piso Conversacional...................................................... 32

2. Estrutura Argumentativa da Discordância........................................ 46

3. Cenário Ilustrativo do Programa 59"'............................................... 52

4. Tema e Subtemas do Primeiro Recorte................................................. 59

5. Tema e Subtemas do Terceiro Recorte............................................. 62

6. Seqüência de Turnos Discordantes................................................... 84

\section{LISTA DE QUADROS}

1. Normas ou Sugestões para Refutar Argumentos............................... 47

2. Posição/ Argumento: $1^{\circ}$ Turno/ $1^{\mathrm{a}}$ Participante.................................. 69

3. Contraposição/ Contra-Argumento: $2^{\circ}$ Turno/ $2^{\text {a }}$ Participante.......... 71/72

4. Posição/ Argumento: $1^{\circ}$ Turno............................................................ 73

5. Posição/ Argumento: $2^{\circ}$ Turno.......................................................... 73/74

6. A Ordem das Evidências: $1^{\circ}$ Turno/ $4^{\circ}$ Turno................................... 77/78

7. Posição/ Argumento: $3^{\circ}$ Turno/ $3^{\circ}$ Participante................................. 79

8. Contraposição/ Contra-Argumento: $4^{\circ}$ Turno/ $4^{\circ}$ Participante........... 80

9. Marcadores de opinião................................................................... 92

10. Intervenções de Turno....................................................................... 99 